\title{
The role of perceptual and cognitive filters in observed behavior
}

Kåre Rumar

From: Human Behavior and Traffic Safety, s 151-170.

Edited by Leonard Evans and Richard C. Schwing (Plenum 1985) 


\title{
From: HUMAN BEHAVIOR AND TRAFFIC SAFETY Edited by Leonard Evans and Richard C. Schwing (Plenum Publishing Corporation, 1985)
}

\section{THE ROLE OF PERCEPTUAL AND COGNITIVE FILTERS IN OBSERVED BEHAVIOR}

\author{
Kåre Rumar \\ Swedish Road \& Traffic Research Institute \\ Linkoping, Sweden
}

\begin{abstract}
Initially the development of man's position in road transport is described and analyzed. It is shown that the large changes have to do with the lack of feedback, new situations from physiological point of view and especially the higher speeds.

The part played by human and technical errors in road accidents is discussed. It is found that most investigations attribute a dominating part to human errors. Although this is believed to be more of an artifact than a true description the results can be used for further analysis. Such an analysis shows that the two most frequent human errors are inadequate human information acquisition and information processing.

A simple descriptive model of the driver in traffic is presented. It is suggested that man's inherited limitations and lack of appropriate experience result in systematic errors in information acquisition and processing. Two inserted constructs

- a perceptual filter

- a cognitive filter

are used to describe road user errors and to generate hypotheses and suggestions of how to meet and overcome some inadequate road user behavior. Special high risk situations (night traffic, peripheral detection, speed) and special high risk groups (inexperienced young drivers), are used to illustrate the ideas in the descriptive model.
\end{abstract}




\section{PURPOSE}

The purpose of this paper is to point out two behavioral phenomena that are considered important for road safety.

- systematic perceptual errors

- systematic cognitive errors

These two types of errors are believed to be serious because they contribute to the development of road accident but are at the same time possible, at least partly, to counterbalance or overcome if they are correctly understood.

In order to understand them we have to look at the evolution of man's role in the road transport system and which human errors that are typical in road accidents.

To explain the functioning of the two types of errors a simple model of driver behavior is outlined in which two filters are illustrating the two types of errors. Finally examples of the effects of the two filters and possible countermeasures are given.

\section{EVOLUTION OF THE ROAD TRANSPORT SYSTEM}

In the first stages of road transport development the problems were mainly technological. Man had large difficulties in creating a reliable, economical, safe and comfortable vehicle that could stand the roads of those days. Man also had large problems with building roads that could take the wear from the vehicles, that could stand various climatic conditions and still remain fairly smooth. But these problems were solved in comparatively short time. What remains is to a large extent optimization.

The development of the road transport systems has followed about the same scheme as most man-machine systems such as manufacturing, weapon systems, home work, sea transport, and many others. In the first stages man was doing the work in direct contact with the environment. The work was to a large extent muscular, the feedback on right and wrong actions was normally instant (see Figure 1).

What has happened the last hundred years is that the advancement of technology has given us equipment (the explosion motor) that has relieved man from most of the muscular tasks. The machines can carry out heavier tasks much quicker and for longer periods than the human muscles. We can now transport, produce, destroy etc. large quantities, at long distances and high speed, with low costs, high precision and low technical failure rate. We have technically sophisticated vehicles and roads.

During the last decade the electronic revolution (small, powerful low cost computers) has entered road transport. This happened earlier in the military, aviation and industrial areas and later in the homes. The purpose of these computers is to relieve man of some of the mental tasks. (See Figure 1). 

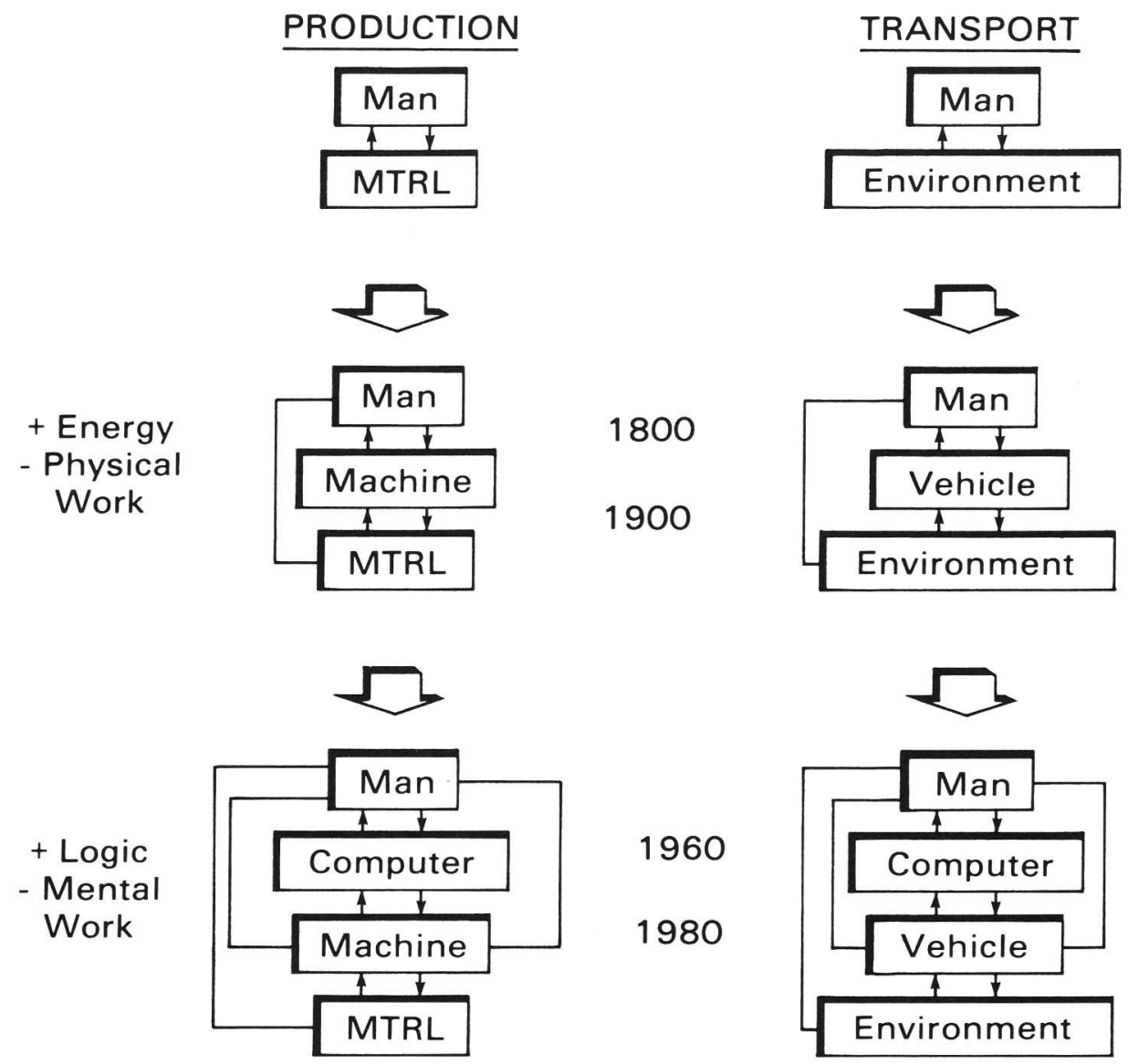

1800
1900
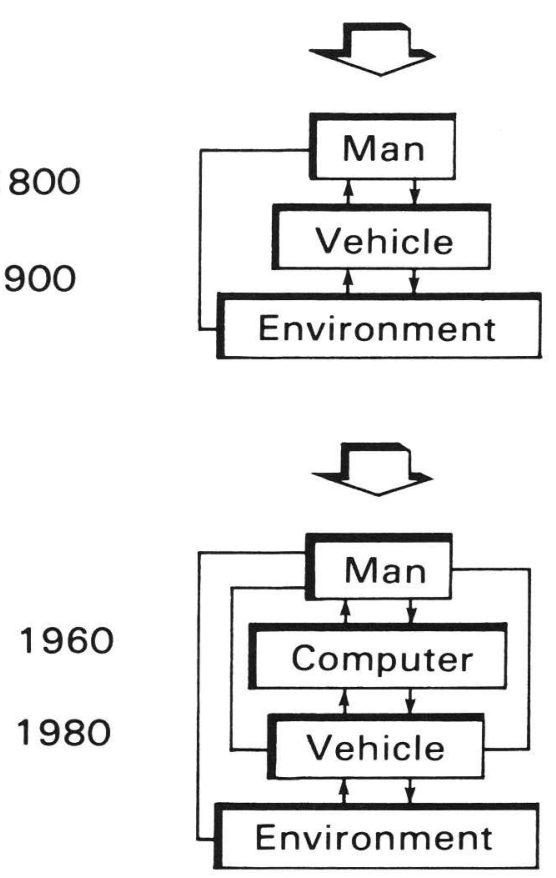

Figure 1. The evolution of the transport system compared with the evolution of the production system. Three stages from walking/handicraft via external energy source to external logics can be identified. The human role has changed considerably; less feedback, higher speeds, larger attentional demands.

In traffic they were first used in traffic regulation systems (e.g. "intelligent" traffic lights) but are now also increasingly used in cars. The next step will be to start communication between the computers along the road and the computers in the car. This is required to develop information, warning and regulation systems to the same technical level as presently cars and roads.

The positive effects of these changes are evident. The effectiveness of transport has increased tremendously. Some even argue that mobility has become too high. Man has reached such freedom to move that the homes, work places, shops, vacation places etc. are often placed in a very awkward position in relation to each other. This is becoming evident in times of shortage of money and energy. But of course increased transport effectivity is a very positive effect.

The speeds, the engines, have however also had some drawbacks. The main obvious ones are safety and environmental problems. By now the relation between accidents and traffic speed is clearly established and widely recognized. The effects of traffic on pollution, noise, vibration etc. are more disputed. But, although the size of these effects is under discussion, the reality of these phenomena is a fact. 


\section{EFFECTS ON HUMAN TASKS}

One effect of this evolution is that the feedback to the driver (e.g. from various vehicle maneuvers) has been reduced, intermittent, disappeared or even reversed. In the old days as for today's babies, almost every action was rewarded or punished. This made the system in a way selfadjusting, selflearning. In road traffic of today roads are smooth, cars are soft and silent, horrible maneuvers can be made normally without anything happening.

Some bad maneuvers (e.g. short following distances) are normally rewarded while the correct maneuver (longer following distance) is often punished.

Another effect is that the characteristics of senses and other functions that developed by mutations, and according to Darwin made us survive, are now often outdated (e.g. night vision, peripheral vision, speed perception). The technical evolution has been so fast that the natural selection and the adaptation of man to his environment are overrun. Another way of expressing the same thing is that we are no longer using natural signs and signals. Therefore mistakes are made.

The third specific effect depending on the two main ones is that man has problems handling the high speeds in which today's transport is carried out. We are made for foot speeds $(\sim 10 \mathrm{~km} / \mathrm{h})$ and are now moving at car speeds $(\sim 100$ $\mathrm{km} / \mathrm{h})$. This has many effects

- we have to focus attention much further away

- information density is much higher

- the variation of speeds between road users is much larger

- it is very hard to predict potential danger points with several high speed vehicles

- the necessary maneuver-time and-distances are proportional to the square of the speed

- a mistake is more difficult to correct and will have more serious consequences (compare air traffic)

- the developed energy (damage) in case of collision is also proportional to the square of speed

In other words the high speeds lead to problems in speed perception, problems in focusing and distributing attention, problems in processing information, estimating difficulties, and making decisions, problems in carrying out maneuvers, and larger effects when mistakes are made.

\section{PART OF HUMAN ERRORS IN ACCIDENTS}

In order to investigate the causes for accidents in some man-machine systems (e.g. aviation, railways, shipping, nuclear power) it has for many years been common to use multidisciplinary accident investigation teams consisting of var- 
ious specialists such as captains, engineers, physicians, and phychologists. Especially within the flight sector this system has been developed and refined. By means of special equipment (e.g. the recording black box) and supported by other techniques (e.g. incident reporting, experimental analysis) the flight accident analysis teams have without doubt been successful in finding accident causes thereby preventing corresponding accidents from happening again.

Therefore it is quite natural that efforts have been made to use the same technique on road traffic accidents. However, so far the success with these efforts has been very limited. Several causes can be mentioned.

- The informational situation is more complicated and much more difficult to trace in the road situation compared to the flight and marine situation.

- The effect of technical deficiencies is much smaller in the road situation.

- The professional qualification of drivers is much lower in the traffic situation and there is a wide range of abilities and qualifications among the millions of drivers.

However, during the last decade some ambitious efforts to overcome previous shortcomings have been presented. A study by Sabey \& Staughton (1975) and an Indiana study by Treat (1980) are two illustrative examples. In both studies they used a statistical and to some extent a clinical case study approach carried out by multidisciplinary teams. Figure 2 shows the main results.

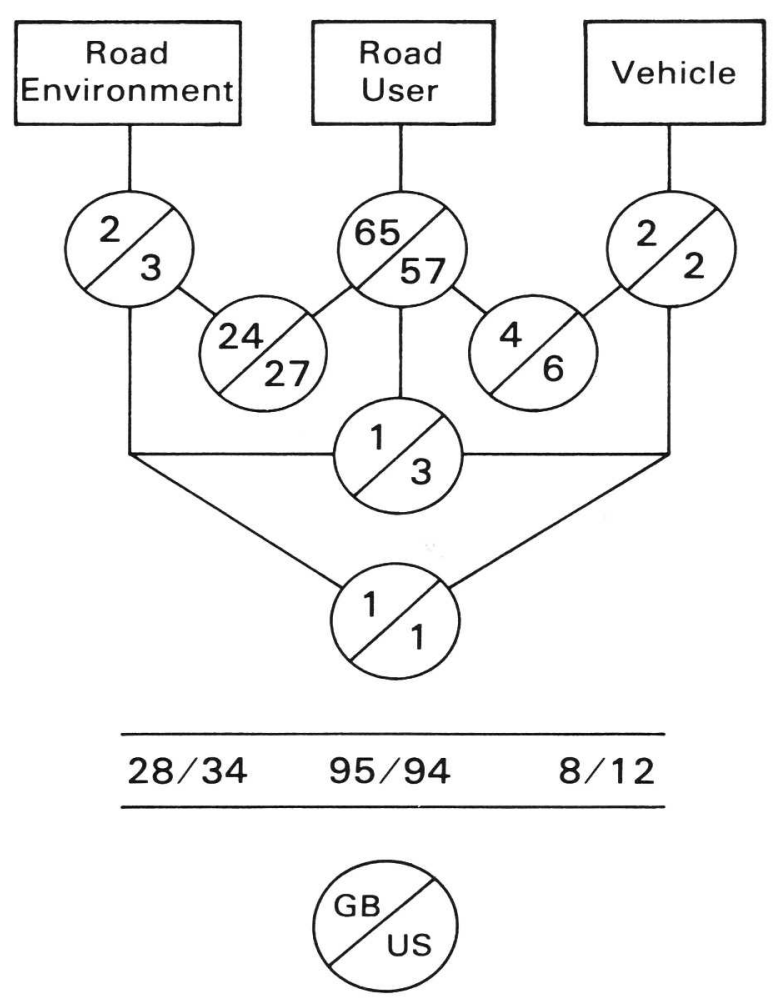

Figure 2. Percentage contributions to road accidents as obtained in a British and a US accident in depth study. 
As can be seen these two completely separate rather large studies of several thousand accidents are almost unanimous in their pointing at the road userthe human factor-as the dominating cause of road traffic accidents. The analysis could be extended further by trying to classify the type of human errors involved (see Figure 3).

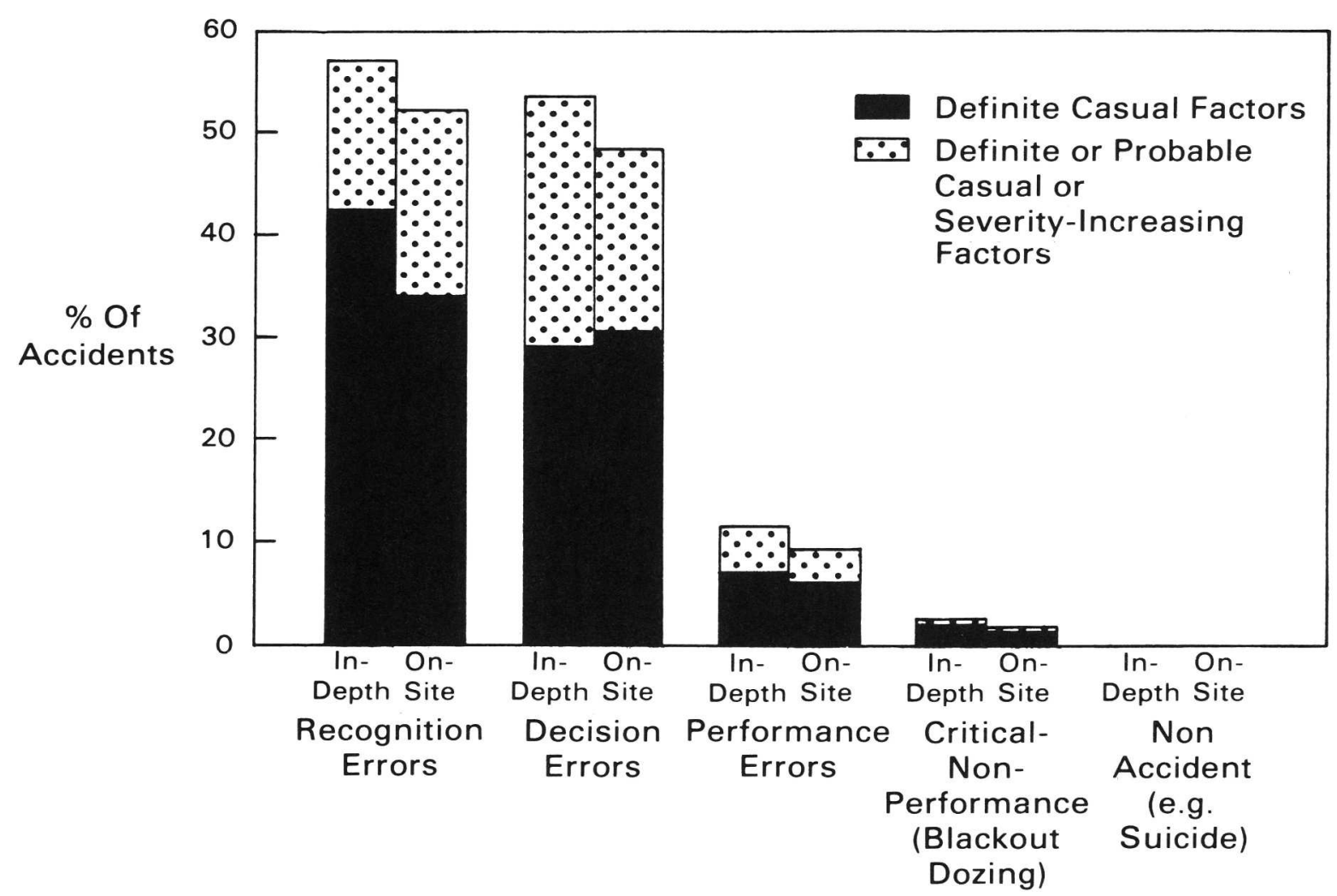

Figure 3. Percentages of accidents in which human factors were identified as definite or probable causal factors (Treat 1980).

As can be seen from Figure 3 recognition errors (perception, comprehension) and decision errors predominate. These types of errors could be assembled under the heading of "inappropriate information acquisition and processing." The next step in the Indiana study was to specify the human errors. In decreasing order of frequency of occurrence the following errors are given:

1. Improper lookout

2. Excessive speed

3. Inattention

4. False assumption

5. Improper maneuver

6. Internal distraction

Here the weakness of this approach becomes evident. Since these and most previous accident investigations lack an explicit theoretical basis the results 
tend to be of very general, common sense, character; they are hard to relate to other types of data, they are hard to communicate to other disciplines and, perhaps most important, they tend to use the human factor as the scrap box. Every accident behind which we do not find any technical error tends to be explained by the human factor. Even the otherwise sensible Japanese White Paper of 1982 lists as a major cause of accidents "failure to drive safely!" (Haight 1983)

The whole idea of asking for the cause to the breakdown of a system is questionable. It is like asking for the cause to floods. The answer is rain. In road traffic accidents the answer is man. But we cannot do very much to influence raining and we cannot change the basic characteristics of man.

The basic conclusion to be drawn from these analyses is that typical human errors contributing to accidents are perceptual errors and decisional errors (What else could it be?) having to do with information acquisition and processing. This coincides well with the explanations given by drivers involved in accidents: "I did not see until too late . ..".

Now, how do these errors develop and what could we do to decrease them?

\section{A SIMPLE MODEL FOR ROAD USER BEHAVIOR}

The model presented here is, needless to say, not a theory-just a working model to illustrate how the initially mentioned two types of errors influence road user behavior. The model is based on several earlier presented models (mainly Goeller 1969, Durth 1971, Englund \& Pettersson 1978, Rumar 1982). The purpose is to give an idea about how road user information acquisition and processing is functioning.

A simple but useful definition of information is "reduction of uncertainty." This means that information is not something in the environment. It is in the road user that perception and experience take the form of information. What is information to one road user, might not be information to another or what is information to one road user at a certain moment might not be information to the same road user at another moment. It is the perceived situation not the physical reality that determines behavior!

This is of vital importance. Road and traffic engineers construct the physical traffic environment (road geometry, alignment, surface, delineation, road signs, traffic signals etc.). Many engineers presume intuitively that the same environment is perceived identically by passing road users. This is not the case. Every individual road user selects his own information.

In Figure 4 an effort is made to present in a simple form the most important functions for the acquisition, selection, and processing of information.

Stimulation from the physical environment reaches the various senses and initiates nervous impulses, a preliminary structuring takes place. Then the information is stored for a short time (seconds) in the short term memory. A more 


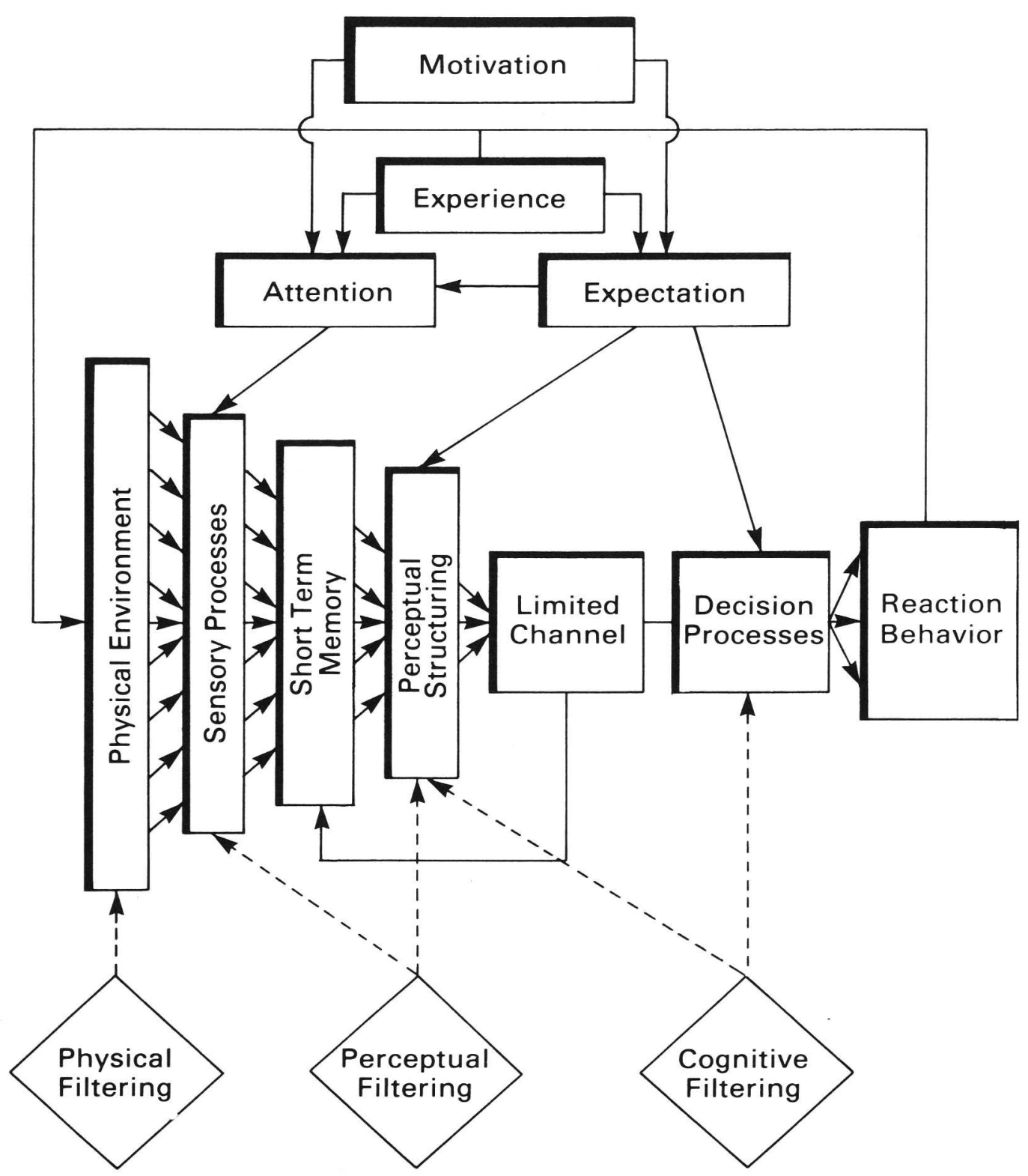

Figure 4. Outline of a model of driver behavior describing the main functions that determine information acquisition and processing. The use of three filters is a way to illustrate three typical errors.

elaborate perceptual structuring and analysis takes place in the central nervous system. The important pieces of information are led throughout a limited channel and used as an external basis for the decisions. Finally the muscles carry out the actions decided which in turn are sensed or are changing the stimulation. These are the more important lower order functions. So far the model is purely mechanistic. But these lower order functions are governed and highly influenced by higher order functions like motives-normally to get to the goal quickly, safely and comfortably but sometimes the motive is to experience the thrill of driving, to get away from something; experience-of previous situations corresponding to the momentary one. Motivation and experience influ- 
ence attention-level and direction; expectation-of what will happen or what will be perceived and which actions that will be appropriate.

In order to simplify this model (which of course already really is too simple) three "filters" are introduced to illustrate typical limitations that may lead to human error, unwanted behavior, road accidents. Let us look at these three so called filters.

It is of course vital to eliminate physical filtering as far as possible. Road users should at least be given the opportunity to perceive and evaluate the situation - his line of sight should not be blocked by depressions in the road, by hedges in crossings, his hearing should not be masked by noise etc. Or may be more important physical filtering should not be allowed unless it is made quite clear that it exists!

Perceptual filtering is mainly dependent on physiological limitations in our senses inherited from our ancestors. We need minimum amounts of energy to detect stimulus, we need minimum differences of energy to be able to separate various stimuli. These threshold values vary with situational conditions and individual characteristics. Examples of situations in which simple perceptual filtering can be found are e.g. night traffic, peripheral detection of vehicles, and perception of speed of oncoming cars. Examples of situations with more complex perceptual filtering are perception of following distances (headways), perception of speed and speed changes in the own car.

Cognitive filtering is more dependent on higher order functions like motives, experience, expectation. An important factor here is the lack of feedback mentioned earlier. But it is also dependent on the limited capacity of information processing. Situations in which cognitive filtering occurs are e.g. influence of road signs, behavior at road crossings, prediction of the motion of other road users, introduction of obvious measures to drive safer (e.g. studded tires), estimation of one's own driving skill and capacity, estimation of risk.

Sometimes the border between perceptual and cognitive filtering is unclear (e.g. in the process of overtaking, in direction of attention).

\section{PERCEPTUAL FILTERING}

During the first phase of the initially mentioned evolution of the transport system man received his basic physiological characteristics. During the last century these characteristics have to a large extent become obsolete; limitations instead of possibilites. This is the basic reason for the perceptual filtering. Let us exemplify.

Man developed to be a daylight creature with daylight vision. But nowadays more and more transport is carried out at night with illumination levels from road lighting and vehicle lighting that are only a fraction (1/10 000) of daylight levels. This means that the receptors in the retina have to work at levels they are not developed for, that the optical system (the eye) has to work under very 
ununiform illumination (glare) which it was not designed for. As a consequence several studies (see e.g. Rumar 1979) show that visual performance (visibility distances, recognition, estimation of location, distance, speed, etc.) is seriously impaired. But drivers do not realize the full impairment and consequently accident rate at night is 2-3 times higher than during day.

Another example is detection of oncoming dangers in the periphery of our visual field. Our ancestors were threatened by attacking animals and other human beings. These oncoming dangers were really moving. To survive we developed a very high sensitivity for motion in the visual periphery. This sensitivity was useful also for man as a hunter, to detect our food easier. But today's most frequent oncoming danger, the automobile, shows no motion (and very little sound). It just grows very slowly on the retina. Therefore it is not really detected in peripheral vision. We have to look almost straight on to detect it ( $\mathrm{Ru}-$ mar 1981). And as was mentioned earlier the most common human error in accidents is "improper look out," the most common explanation from drivers in accidents is "I did not see until too late. . . ."

These two examples are very peripheral to their character. Let us take a couple of examples with more of a central aspect. From our ancestors we have inherited a healthy respect for heights. This respect can be found even in babies (Gibson 1966). Very few of us lean out very far from a window on the third floor. But that height corresponds to a speed of $50 \mathrm{~km} / \mathrm{h}$. And almost none of us has any respect for that speed-not babies, not adults. Most people think they can easily handle the effects of such speeds. They believe, e.g., that a seat belt is not needed in such speeds since you can protect yourself with your arms; they believe intuitively the stopping distance is almost zero, etc. And the feed back is not frequent enough to change these beliefs. We lack a basic healthy respect for speed. It is therefore not surprising that speed is one of the variables that correlates best with accidents. High speed is the second most frequent human error found in the accident in depth analyses.

As a final and more hypothetical example of perceptual filtering we chose headways. Since we lack respect for speed we generally drive with too short a distance to the car ahead of us. There are plenty of studies (e.g. Sten 1979, Evans \& Wasielewski 1982) and accident statistics showing this. And the headways do not vary with speed to the extent they should. The enormous queue accidents now and then occurring on motorways show this. It seems that drivers are mainly perceiving the distance and the distance changes to the car ahead of them and more or less neglect the speed of the cars. Now this is a hypothesis that to our knowledge has not yet been tested.

\section{COGNITIVE FILTERING}

While there are mainly inherited physiological characteristics behind the perceptual filtering the reasons for the cognitive filtering are of a more psychological nature, depending partly on the specific motives of a road user, partly on the 
specific experience of a road user and partly on the limited information processing capacity of all road users. A main factor behind the specific motivation, experience and expectation of road users is the limited feed back offered in road traffic (Wilde 1981). Motivation and experience influence the direction and level of attention and expectation which in turn influence sensory processes (e.g. eye movements) perceptual structuring (e.g. we see what we expect to see) and decision processes (we often get very prejudiced also in traffic). The function of this process is to filter information, to bias decisions (cognitive filtering).

In order to give the road users information along the road we use road signs - large colored metal sheets with symbolic or written messages. The information might be prohibitions, warnings, route guidance, touristic etc. All of them are put up by the authorities which also believe they are used by the drivers. But they are not due to various types of cognitive filtering. Road signs are probably the best example of cognitive filtering.

But the very first stage of road sign registration is probably influenced by perceptual filtering. The attention of man is not $100 \%$ continuous. That is to say we can never expect man to see every sign. There is some discussion concerning the proportion of misses to be expected. Johansson \& Rumar (1966) claim about $10 \%$ misses while Summala \& Nåătänen (1974) obtained about 1\% misses. These differences are probably due to subject level of motivation. There are also indications of perceptual problems at lower sign contrasts (e.g. Johansson \& Backlund 1970, Summala 1984).

But the main filtering is of a cognitive nature. Several studies have shown very low effects, very low registration of some signs (e.g. general warning, warning for pedestrian crossing) and better but not good effects for other signs (e.g. speed limit, road damage) (Johansson \& Rumar 1966, Undeutsch 1963, Summala \& Hietamäki 1984). The main difference between these signs is the importance drivers ascribe to them, based on experience. Drivers have passed e.g. general warning signs so often without having to do something about it without any positive feed back, that the motivation to take in and use information from that and comparable signs is very low. The importance of feedback is shown e.g. by Nygaard (1981). He studied the effect on driver behavior improved considerably when pedestrians were visible in the vicinity of the crossing. Comparable results have been obtained at road works. These differences between behavioral effects of various signs are even more pronounced in bad weather conditions (Johansson \& Backlund 1970).

That last finding leads over to the fact that the human limited information channel might become overloaded in situations with very high information density-e.g. city street crossings. Studies of how many road signs can be perceived and remembered simultaneously have been made (Klebelsberg \& Kallina 1960, Undeutsch 1963, Turtola 1969, Cole \& Jenkins 1978). The results show that only about two signs are effective at the same time. Compare such results with the forest of road signs existing in many cities and road crossings.

Another example of cognitive filtering related to road signs is to be found by studying priority behaviors in road crossings. A normal rule in right hand traffic 
is to give priority to traffic coming from the right side (right hand rule) unless the crossing is signed with stop or yield signs. A study of driver behavior at road crossings carried out by Helmers \& Aberg (1978) shows, however, that while drivers mainly follow the information given by these two signs (which give feedback and have a high motivation value) the behavior in unsigned crossings is quite different from the official rule (See Table 1). Drivers do not behave according to the rule, they use other more natural criteria for prioritye.g. through road, larger road, road with faster traffic, road with heavier traffic has priority. In other words we have a normal rule that is used by traffic courts in all situations and by some drivers in some situations. But there is obviously also a competing informal rule as a result of cognitive filtering followed by other drivers. It is not surprising that accidents in crossings constitute one of the most common accident types.

The young male driver has the best vision, the quickest reactions and often the best driving skill of all drivers-and he knows it. But he also has a reputa-

\section{TABLE 1}

Driver Knowledge About Correct Behavior and Driver Real Behavior (\%) in Four Types of Intersections

Type of Intersection

Signed:

Right of Way

Knowledge

\begin{tabular}{r|rr|r} 
& \multicolumn{3}{|c|}{ Behavior } \\
\hline+ & + & - & \\
\hline & 92 & 4 & 96 \\
& 4 & 0 & 4 \\
\hline & 96 & 4 & 100
\end{tabular}

Signed: $\quad$ Give Way

Knowledge

\begin{tabular}{r|rr|r} 
& \multicolumn{3}{|c|}{ Behavior } \\
\hline+ & 100 & - & \\
- & 0 & 0 & 100 \\
\hline & 100 & 0 & 0 \\
\hline & & 0 & 100
\end{tabular}

No Signing: $\quad$ Right Hand Rule 4 Way $X$-ing

Knowledge

\begin{tabular}{r|rr|r} 
& \multicolumn{3}{|c|}{ Behavior } \\
\hline+ & 26 & - & \\
\hline- & 0 & 26 & 74 \\
\hline & 26 & 74 & 100
\end{tabular}

No Signing: Right Hand Rule 3 way $X$-ing

Knowledge

\begin{tabular}{r|rr|r} 
& \multicolumn{3}{|c|}{ Behavior } \\
\hline+ & 5 & - & \\
\hline- & 0 & 52 & 57 \\
\hline & 5 & 95 & 100
\end{tabular}


tion for having the worst accident figures of all not intoxicated driver groups. Why? Well, with some effort one way of explaining it is by cognitive filtering. According to Johansson (1982) it is not an effect of not knowing where the difficulties in traffic are. This seems to be fairly independent of amount of driver experience. It is probably because he underestimates the difficulties or overestimates his own capacity or both (Spolander 1983). This results in very aggressive driving. Spolander argues that the driving skill of women of the same age (biological and license), mainly due to more limited driving experience, probably is worse than that of men. But they overestimate the traffic difficulties and/or underestimate their skill. Therefore they drive more defensively and therefore the accident risk of these two groups is roughly the same. The filter that the young men suffer from is the knowledge of being in top physical condition and top driving skill. They really believe they are the best-also as drivers (Spolander 1983). This filter stops them from realizing that road traffic means new tasks that they cannot handle. (See Figure 5) And there is not feedback enough to take that illusion from them (Wilde 1981).
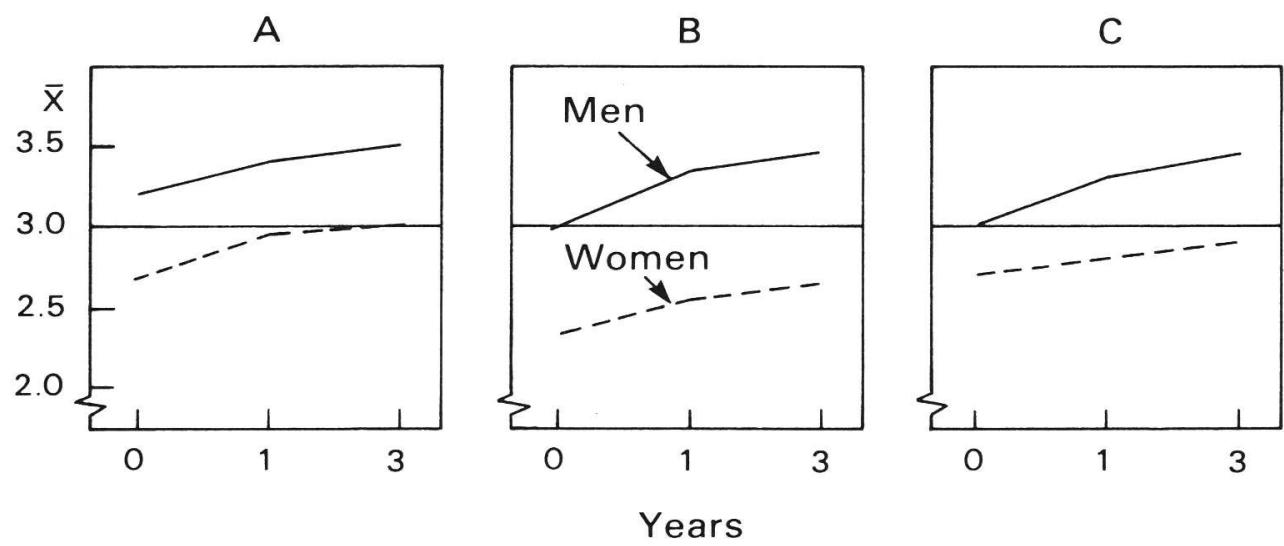

Figure 5. Subjective driving skill in relation to Swedish average $(\overline{\mathrm{x}}=3.0)$ among male and female drivers who have had their license 0,1 , and 3 years. A: To react fast, B: To handle an involuntary skid, C: To drive fast if it is necessary.

\section{CONCLUSIONS}

This model and these so called filters are not possible to test, to verify or falsify. Almost any behavior could be explained within their framework. But they serve the purpose to outline for road safety people in simple terms two types of human errors that are considered common and critical. They may serve the purpose of generating ideas and experiments that are testable.

A descriptive model of driver behavior has been outlined. This model contains two constructs called filters to illustrate and explain two types of common and systematic errors that drivers do (perceptual and cognitive). The perceptual errors are of a general ecological, physiological nature and can be traced back to our ancestors. The cognitive errors have a more psychological and immediate 
background. They are mainly an effect of specific driver experience and motivation.

Main countermeasure suggested for the perceptual errors is

- Adapt environment to man's limitations (e.g. lighting, retro-reflectors).

A secondary possibility is

- Inform man of his limitations. Let him experience these limitations (e.g. speed, headways) at least during training.

Proposed main countermeasure for the cognitive errors is

- Give man the feedback present traffic does not offer.

Other possibilities are

- In road user training emphasize situations in which cognitive errors are common.

- Try to change driver's basic values and attitudes to safety in road transportation and road transport.

\section{REFERENCES}

Cole, B.L. \& Jenkings, S.E. Conspicuity of traffic control devices. Austrialian Road Research Board. Internal report, 1978.

Durth, W. Die optischen Informationen als Kriterien für die Gestaltung der Überholstrecke. Strassenbau, Verkehrstechnik und Verkehrssicherheit. 1971, 15, 31-32.

Englund, A. \& Pettersson, H.E. The accident commision of the Insurance companies (in Swedish). Road Safety Committee (TRK) Rapport 1, Stockholm. 1978.

Evans, L. \& Wasielewski, P. Do accident-involved drivers exhibit riskier everyday driving behavior. Accident Analysis and Prevention, 4, 57-64, 1982.

Gibson, J.J. The senses considered as perceptual systems. Houghton Mifflin, Boston. 1966.

Goeller, B.F. Modeling the traffic safety system. Accident Analysis and Prevention, 1, 167-204. 1969.

Haight, F.A. Road safety: A perspective and a new strategy. The Pennsylvania Transportation Institute, USA. Working paper 29, 1983.

Helmers, G. \& Aberg, L. Driver behavior in intersections as related to priority rules and road design. National Swedish Road and Traffic Research Institute (VTI). VTI Rapport 167. 1978.

Johansson, R. The relation between subjective and objective accident risk. (In Swedish) Transport Research Delegation, Sweden. Report 1982:9.

Johansson, G. \& Rumar, K. Drivers and road signs. Ergonomics 9, 57-62. 1966. 
Johansson, G. \& Backlund, F. Drivers and road signs. Ergonomics 13, 6, 1970.

Klebelsberg, D. \& Kallina, H., Wieviele Verkehrszeichen können gleichzeitig wahrgenommen werden? Kriminalistik, 14, 1960.

Nygaard, B. A pilot study of the effect of feedback at a pedestrian crossing. $\mathrm{Na}$ tional Swedish Road and Traffic Research Institute (VTI). Memo. 1981.

Rumar, K. The visual environment in road traffic. Proceedings from CIE 19th Session, Kyoto, Japan, Publication 50. Paper 79-01. 1980.

Rumar, K. Daylight running lights in Sweden-Pre-studies and experiences. SAE Technical Paper 810191. Detroit. 1981.

Rumar, K. The human factor in road safety. Invited paper to the 11th Australian Road Research Board Annual Conference, 1981, Proceedings, 11, Part 1, 63-80, 1982.

Sabey, B.E. \& Staughton, G.C. Interacting roles of road environment, vehicle and road user in accidents. 5th International Conference of the International Association for Accident and Traffic Medicine, London, 1975.

Spolander, K. Accident risks of drivers-a model tested on man and woman (in Swedish) Swedish Road and Traffic Research Institute (VTI). Rapport 260. 1983.

Sten T. Safety marginals by driving. (in Norwegian) Technical University of Norway. Internal report. 1979.

Summala, H. \& Näätänen, R. Perception of highway traffic signs and motivation. Journal of Safety Research, 6, 4. 1974.

Summala, H. \& Hietamåki, J. Drivers immediate response to traffic signs. Ergonomics, 27, 2, 205-216, 1984.

Treat, J.R. A study of precrash factors involved in traffic accidents. Highway Safety Research Institute (HSRI). USA. The HSRI Research Review 10, 6, 11, 1. 1980.

Turtola, K. Perception of simultaneously presented traffic signs. Universiy of Tampere, Finland, Report 42, 1969.

Undeutsch, U. Die Auffassungsfähigkeit für Verkehrszeichen. Zeitschrift für Verkehrssicherheit, 9, 1963.

Wilde, G.J.S. Objective and subjective risk in drivers' response to road conditons: The implications of the theory of risk homeostasis for accident aetiology and prevention. Seminar on the Implications of Risk Taking Theories for Traffic Safety, West-Berlin. 1981.

\section{DISCUSSION}

John Michon (University of Groningen, The Netherlands)

I have two points. One concerns the moving animal and our peripheral vision. I would think, if you're being chased, the animal chasing you would probably be moving toward you in a straight line, but I don't see quite the difference with the- 


\section{Kåre Rumar}

Yes, the attacking animal was moving against us in a straight line, but it contained with few exceptions "internal" motion of legs, body, head, etc. This motion attracts the attention in the periphery of the visual field. The only exceptions I can think of are a diving bird and maybe an attacking fish under water. Today's enemy, the automobile, contains no visible internal motion. There is nothing to attract peripheral attention (detection).

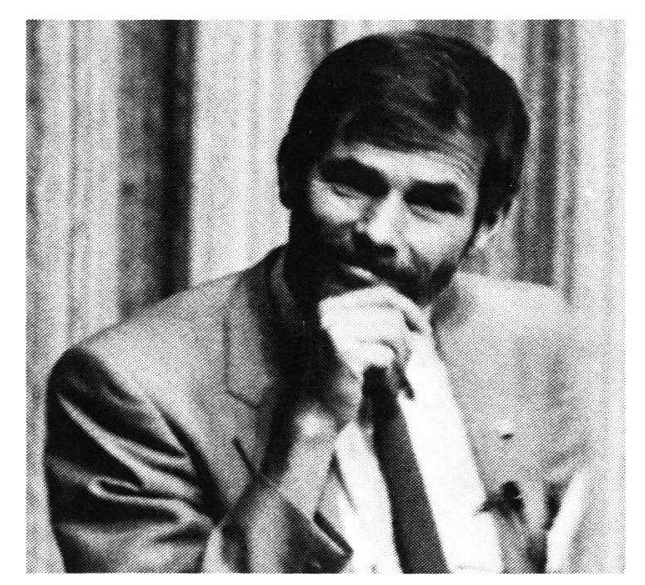

Kåre Rumar

\section{John Michon}

More important, I think, is the other point. You are no doubt an authority about perceptual filtering but even though you say that that's where our natural instincts are, I was quite surprised that you do not introduce something like an "executive filtering" which would take care of the motor limitations, that kind of thing.

\section{Kåre Rumar}

Yes, that is a good idea. The reason I did not make it is that, according to results from accident in-depth studies, motor problems constitute a minor part of human errors.

\section{David Shinar (Ben Gurion University, Israel)}

This is not a question, it's a comment; and I think this may be the best place I could ever have to make it.

You've cited this study by Treat, and I was involved in that study, and it gets cited a lot for the wrong reason, and I think that may have-I'm not sure-you didn't say much about it but it may have been implied. 
That study showed behavior that, had it been different, the accident would've been prevented. That study never purported to say these are the cause of the accidents. And so the comment, you know, that was implied and the reaction to it was here. I would never quite say it that way in the report itself.

\section{Kåre Rumar}

Yes, I accept that criticism. I have stretched the results of the Treat study. But it was good for my purpose.

\section{(LAUGHTER)}

\section{Pat Waller (The University of North Carolina)}

I can understand the peripheral vision and how important it is for the pedestrian and perhaps the cyclist, but when you're driving a car, from the standpoint of the driver, when you're moving, to what extent does peripheral vision really matter that much? Because by the time something is coming from the side, you're going to be past that point. And we've had difficulty actually showing relationships between restricted visual field and crash experience.

\section{Kåre Rumar}

Peripheral vision in my opinion begins only a few degrees from the fixation point. It is not only a physiological threshold, it is also a threshold of expectation (you do not see what you do not expect) that the daylight running lights can help to overcome (compensate for).

Peripheral vision is used in several driver situations where detection of other cars is important (e.g. oncoming car in overtaking situation, oncoming car on road you intend to cross, in rear view mirror, approaching car from behind).

This figure (page 168) shows the relation between daylight running light intensity and general sky illumination $20^{\circ}$ peripheral detection distance as obtained in experimental studies. 


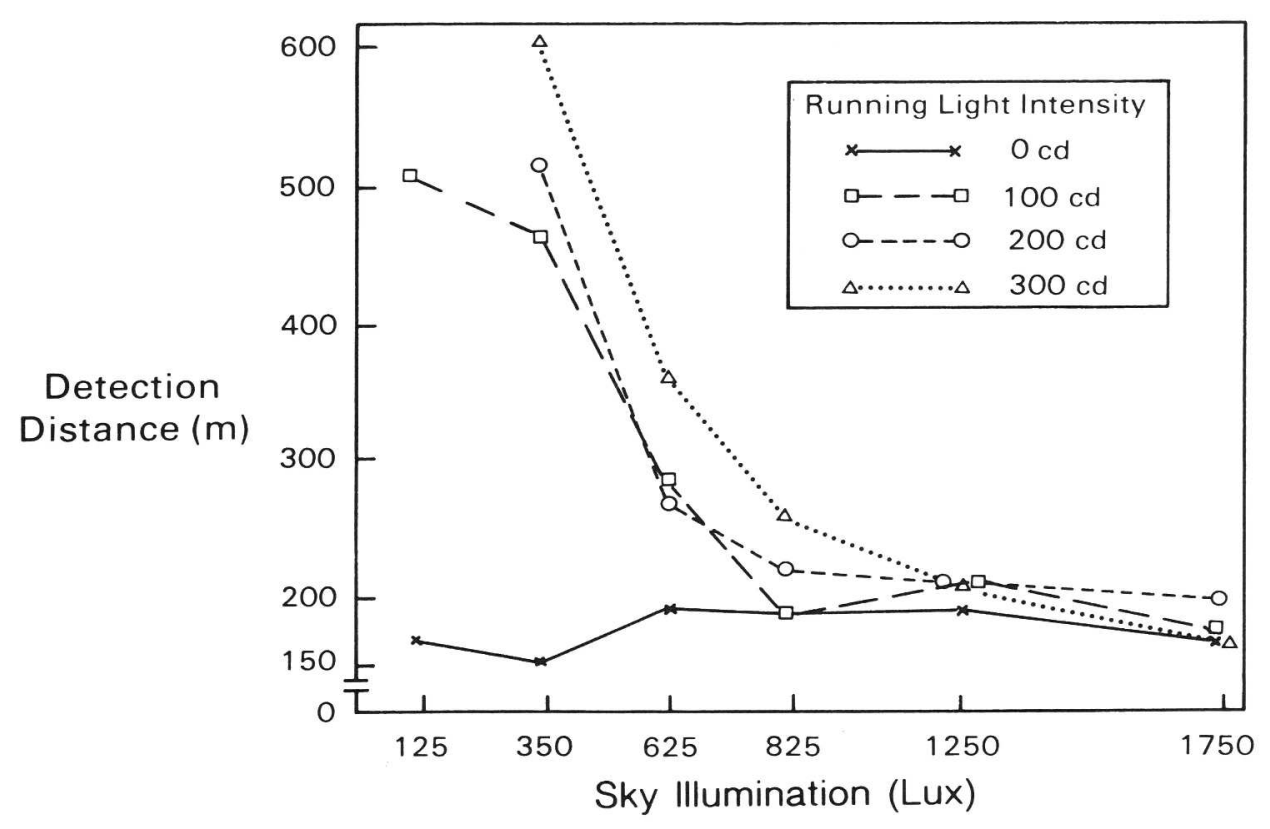

Accident statistics analyses show that after introduction of compulsory daylight running lights in Sweden, daylight head on collisions between cars decreased by about $10 \%$ and daylight angular collisions between cars decreased by somewhat less while daylight collisions between car and cyclist/pedestrian decreased by $15-20 \%$.

\section{Pat Waller}

Right, I believe the lights-on data. I wasn't questioning your data. I was questioning the extent of the importance of the peripheral vision?

\section{John Michon}

May I add one little thing.

Peripheral vision is very important with respect to keeping your heading direction and estimating your road speed and that's probably more important or at least as important a function of the peripheral visual system as it is for observing another object.

\section{Kåre Rumar}

Yes, I agree peripheral vision is at least as important for course and speed estimation as for detection. But here detection was the problem and daylight running lights are part of the solution. 


\section{Leonard Evans (General Motors Research Laboratories)}

I don't want to use this meeting to give a commercial for another one, but at the Transportation Research Board meeting in January, I'll be giving a paper called "Human Behavior Feedback and Traffic Safety," where I look at a total of 26 different safety counter-measures, or things that are expected to affect safety; I find that you get a wide variety of responses.

One in particular that I looked into was the effect of having only one eye. Apparently the accident rates of monocular drivers are, if anything, lower than those for drivers with two eyes. I mention this as possibly relevant to the discussion that was going on earlier, because I wondered if the same sort of thing might just apply to those with diminished peripheral vision. In other words, people are behaving in a way that reflects their own special capabilities. The one-eyed driver may be safer because he knows he's a one-eyed driver.

\section{Kåre Rumar}

We are in fact at the moment in the middle of a project where we compare peripheral detection for drivers with normal visual fields with drivers with losses in their peripheral visual fields. The preliminary results show that most drivers with defects in their visual fields suffer from it in the respect that they have longer detection times for cars appearing in the periphery, often they also had a worse accident record in those angles too. But some of them manage to compensate for their handicap. Their detection times are not longer than for normal drivers and there is no indication that their accident record is worse than normal.

\section{Leonard Evans}

When I mentioned this to somebody, they asked me if I was advocating as a safety measure that people get an eye poked out-

\section{(LAUGHTER)}

Scott Geller (Virginia Polytechnic Institute and State University)

One last question.

Murray Mackay (The University of Birmingham, U.K.)

I'd like to just contribute to the confusion on this question of peripheral vision. We found that older people have more intersection collisions than References pp. 164-165 
younger people. You have to be careful, however, to standardize on speed because if you go fast enough you'll never have a side impact.

\section{(LAUGHTER)}

Older people tended to be slower, but even allowing for that, it does seem to be quite important, the question of peripheral vision at intersections. And I think the running light question, therefore, is going to have its biggest answer there.

\section{Kåre Rumar}

I have no experimental evidence but several statements from older people that they really appreciated and noticed the positive effects of daylight running lights in situations like the ones Murray Mackay mentioned-e.g. older people wanting to cross a street as pedestrians or drivers.

\section{Scott Geller}

Patricia, one more question.

\section{Pat Waller}

Well, I just wanted to comment. We found the difference in the kinds of crashes that people had so that the ones with the more limited peripheral vision did have more intersection crashes or side swipe crashes but they had fewer of the others. And so if you looked at the total crashes, we found no differences putting it in terms of driver licensing, whether or not you could justify including it. It seems to me it ought to make a difference. It may be there, we just couldn't find it. That doesn't mean it's not there.

\section{Kåre Rumar}

Okay. 
,

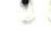

